\title{
Morphology of the axial skeleton of seven bat genera (Chiroptera: Phyllostomidae)
}

\author{
PABLO J. GAUDIOSO, M. MÓNICA DÍAZ and RUBÉN M. BARQUEZ
}

\author{
Programa de Investigaciones de Biodiversidad Argentina/PIDBA, Programa de Conservación de los \\ Murciélagos de Argentina/ PCMA, Facultad de Ciencias Naturales e IML, Universidad Nacional \\ de Tucumán, Consejo Nacional de Investigaciones Científicas y Técnicas/ CONICET, PJG, RMB, \\ MMD, Fundación Miguel Lillo (MMD), Miguel Lillo 205, 4000, Tucumán, Argentina
}

Manuscript received on February 1, 2017; accepted for publication on June 28, 2017

\begin{abstract}
Here we present detailed descriptions and comparisons of the axial skeleton of seven species of bats belonging to five subfamilies of Phyllostomidae of different trophic guilds. The material examined consisted of 34 complete skeletons of seven species. For five of the studied species, previous descriptions have not been conducted, and for the vampires only limited information is available, so that descriptions for these species are here completed. The axial skeleton has characters that allow grouping of the species phylogenetically of the same subfamily and by feeding habits. At the same time, there are characters that associate species from different subfamilies with different types of diet or ways to obtain food.
\end{abstract}

Key words: Argentina, Chiroptera, description, morphology, Phyllostomidae.

\section{INTRODUCTION}

The study of postcranial anatomy in mammals goes back to the 18th century, but investigations oriented to finding postcranial characters for phylogenetic or evolutionary studies began only in the $20^{\text {th }}$ century. These studies increased and improved the descriptions and identification of species in different groups of mammals (e.g. Argot 2003, Prochel and SánchezVillagra 2003, Sargis 2007, Sargis and Dagosto 2008, Flores and Díaz 2009, Morgan 2009, Hautier et al. 2010); and these characters have also provided crucial data for taxonomic, phylogenetic, evolutionary, and morphofunctional studies (e.g. Salton and Sargis 2008, Morgan 2009, O'Leary et al. 2013).

Correspondence to: M. Mónica Díaz

E-mail: mmonicadiaz@yahoo.com.ar
Despite this innovative research in mammalogy, bats have received cursory attention regarding studies that examine their postcranial anatomy (e.g. Vaughan 1959, 1966, 1970a, b, Vaughan and Bateman 1970, Walton and Walton 1970a, b, 1973, Altenbach 1979, Fenton and Crerar 1984, Panyutina et al. 2015). Some studies include certain postcranial characters in the analysis of evolutionary and phylogenetic relationships or in ecological studies (e.g. Novacek 1987, Simmons 1994, Wetterer et al. 2000, Simmons and Conway 2001, Gunnell and Simmons 2005, Velazco 2005, DesRoche et al. 2007, Tavares 2008, Tejedor 2011, O'Leary et al. 2013), being the study of O'Leary et al. (2013) one of the phylogenetic analysis that included more postcranial characters among mammals; but detailed studies of the postcranial elements of bats are still scarce (Martinez 2010), and have not been 
analyzed in relation with different trophic guilds. This scarcity of studies on postcranial elements is surprising because bats are considered as a model for the study of the anatomy for the great diversification in their trophic niches, which has led to the development of many investigations about variations in the shape of the skull, mandible and teeth, particularly with regard to the type of food they consume (e.g. Freeman 1981, 1984, 1988, 1995, 1998).

No species of bat in Argentina has been studied in detail regarding its postcranial skeleton. Based on this absence of published information, and facing a new perspective in that we have obtained complete skeletons of many species, we decided to conduct a detailed description in order to obtain a morphological pattern that permits us to examine the relationships between the way of obtaining food and the structure of the elements of the axial skeleton. In this regard, we studied, described, and compared each postcranial element of the axial skeleton of seven species of phyllostomid bats. The Neotropical family Phyllotomidae, the second most speciose of Chiroptera, has a high ecological and phylogenetic diversity including 11 subfamilies and 60 genera (Cirranello et al. 2016). The phyllostomid bats have a high diversity in diet, including omnivorous, insectivorous, carnivorous, nectarivorous, frugivorous, and sanguivorous species; also have a large morphological diversity, large range of body size, wing shapes, and flight behavior (Norberg and Rayner 1987, Freeman 1998, Cirranello et al. 2016). In this study, seven species belonging to five subfamilies and five trophic guilds are included.

\section{MATERIALS AND METHODS}

Specimens of the subfamilies Desmodontinae, Glossophaginae, Micronycterinae, Phyllostominae, and Stenodermatinae (Phyllostomidae) were collected for this study and prepared as complete skins, skulls and skeletons.
The material, completely cleaned with dermestid beetles, consisted of 45 axial skeletons of seven species from five trophic guilds (sanguivorous, nectarivorous, carnivorous, insectivorous, and frugivorous). Additionally, we studied 20 other axial skeletons of nine species from other families, which were used for comparative purposes. All the specimens are now deposited at the "Colección Mamíferos Lillo" (CML), University of Tucumán, Tucumán, Argentina (see Appendix S1 - Supplementary Material).

The detail of subfamily-feeding guilds and studied species (in parentheses) are as follows: Phyllostominae-carnivorous (Chrotopterus auritus), Micronycterinae -insectivorous (Micronycteris microtis), Glossophaginaenectarivorous (Anoura caudifer), Stenodermatinaefrugivorous (Artibeus planirostris and Sturnira erythromos), and Desmodontinae-sanguivorous (Desmodus rotundus and Diaemus youngi). The subfamily classification follows Baker et al. (2016), Cirranello et al. (2016), and Rojas et al. (2016).

In addition, a diaphanized specimen of vampire bat (Desmodus rotundus) prepared following the techniques of Taylor and Van Dyke (1985), was used to facilitate the observation of the bones in their natural position, and to make a more accurate description of the studied dry skeletal elements. The axial skeleton includes skull, laryngeal skeleton, spine, and thoracic cage (ribs and sternum); but in this study we only describe the postcranial elements. The skeletal elements were described in size, shape and orientation. We included only adult specimens, as determined by the degree of fusion of the phalangeal epiphysis (complete fusion in adults), and males and females in order to analyze sexual dimorphism.

The bones were observed with a stereoscopic microscope Nikon SMZ 745T. For describing the anatomical characters, we used the traditional terminology for terrestrial mammals; for anatomical nomenclature and criteria for the position of the 
different skeletal elements we followed Vaughan (1959, 1970b), Walton and Walton (1970a) and Altenbach (1979), and for the divisions of the axial skeleton we followed Vaughan (1970b).

The measurements were taken with digital callipers to the nearest $0.01 \mathrm{~mm}$ : greatest length of dorsal arch of atlas (GLDA), maximum length from craniad to caudad edge in the dorsal arch; greatest length of ventral arch of atlas (GLVA), maximum length from craniad to caudad edge in the ventral arch; greatest height of spinous process of axis (GHSP), maximum length taken from the base of the dorsal arch of axis to the dorsal tip of the spinous process; greatest height of axis (GHA), maximum length taken from the base of the ventral arch of the axis to the dorsal tip of the spinous process (Fenton and Crerar 1984, Shapiro 1995, Fig. 1).

\section{RESULTS}

\section{DESCRIPTION}

Axial skeleton. All species analyzed have seven cervical vertebrae, while the number of elements is variable in other types of vertebrae, specifically 11 13 thoracic, 4-7 lumbar, sacral vertebrae fused into a single bone (the sacrum), and $0,1,3$ to 6 caudal vertebrae. Phyllostomidae is one of the families of bats where the only vertebral fusion observed is the sacrum, three other locations of vertebral fusions are found in other families (see Larkey et al. 2012).

Atlas (Fig. 2). The atlas (as well as the axis) is one of the largest skeletal elements of the vertebral series, with exception of the sacrum. The dorsal neural arch is either flattened (in D. rotundus, $C$. auritus, and M. microtis) or curved (in D. youngi, A. caudifer, A. planirostris, and S. erythromos), but in all species is antero-posteriorly longer than the ventral arch (see Table I), and at the middle anterior region has an inclined surface. The atlantal foramen has a single opening in all species, but in D. youngi we observed two openings, which

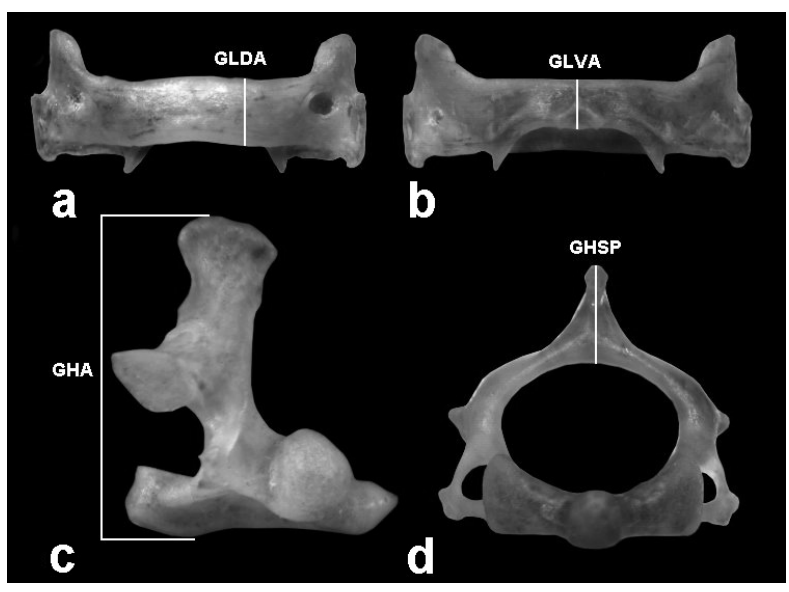

Figure 1 - Measurements: a) GLDA, greatest length of dorsal arch of atlas; b) GLVA, greatest length of ventral arch of atlas; c) GHA, greatest height of axis; d) GHSP, greatest height of spinous process of axis. See Materials and Methods for definition of the measures.

may be an individual variation, since we have examined only one specimen (Fig. 3b). The size of the foramen varies proportionally with respect to the size of the atlas, being small in D. youngi, D. rotundus, and S. erythromos, large in C. auritus, $M$. microtis, and A. planirostris, and very large in A. caudifer (Fig. 3a). The transverse processes are laminar in all species, bilobed in A. caudifer and $M$. microtis, and simple in the remaining species; their position is oblique in a sagittal plane. The anterior and posterior openings of the transverse foramen are variable in size; in D. youngi and $S$. erythromos the posterior opening is greater than the anterior, in D. rotundus and M. microtis they are subequal, and in A. caudifer, C. auritus, and A. planirostris the anterior is greater than the posterior. Comparatively, the ventral tubercle is slightly visible in A. caudifer, evident in D. youngi, C. auritus, M. microtis, A. planirostris, and $S$. erythromos, and well developed in D. rotundus (Fig. 2). The shape of the tubercle is variable, from complex with two lateral ridges that join posteriorly to yield a tongue-like shape in $D$. rotundus, to subdivided into two small central tubercles in $A$. caudifer, to simple and located on the rear edge in the remaining species. The ventral processes 
TABLE I

Measurements in mm, mean, standard deviation, and number of specimens of each analyzed species. Acronyms: GLDA, greatest length of dorsal arch of atlas; GLVA, greatest length of ventral arch of atlas; GHSP, greatest height of spinous process of axis; GHA, greatest height of axis; \%, percentage of GHSP in GHA.

\begin{tabular}{|c|c|c|c|c|c|}
\hline & GLDA & GLVA & GHSP & GHA & $\%$ \\
\hline \multirow[t]{3}{*}{ Desmodus rotundus } & 1.54 & 1.18 & 1.71 & 4.88 & \\
\hline & $1.21-1.69$ & $1.04-1.27$ & $1.45-2.09$ & $4.64-5.11$ & $31.3-41.3$ \\
\hline & 7 & 7 & 7 & 7 & \\
\hline \multirow[t]{3}{*}{ Diaemus youngi } & 1.4 & 1.21 & 1.63 & 4.66 & \\
\hline & --- & --- & --- & --- & 35.0 \\
\hline & 1 & 1 & 1 & 1 & \\
\hline \multirow[t]{3}{*}{ Anoura caudifer } & 1.33 & 0.44 & 1.38 & 3.72 & \\
\hline & $1.14-1.43$ & $0.41-0.46$ & $1.27-1.52$ & $3.57-3.94$ & $35.6-38.6$ \\
\hline & 4 & 4 & 5 & 5 & \\
\hline \multirow[t]{3}{*}{ Micronycteris microtis } & 0.73 & 0.46 & 0.86 & 2.80 & \\
\hline & $0.58-0.81$ & $0.44-0.49$ & $0.83-0.91$ & $2.74-2.89$ & $29.6-31.5$ \\
\hline & 3 & 3 & 4 & 4 & \\
\hline \multirow[t]{3}{*}{ Chrotopterus auritus } & 2.69 & 1.45 & 2.75 & 6.66 & \\
\hline & $2.56-2.84$ & $1.30-1.55$ & $2.52-3.19$ & $6.26-7.15$ & $38.4-44.6$ \\
\hline & 8 & 8 & 9 & 9 & \\
\hline \multirow[t]{3}{*}{ Sturnira erythromos } & 1.02 & 0.66 & 1.08 & 3.78 & \\
\hline & $0.89-1.26$ & $0.47-0.79$ & $0.85-1.34$ & $3.46-3.99$ & $24.0-34.4$ \\
\hline & 9 & 9 & 9 & 9 & \\
\hline \multirow[t]{3}{*}{ Artibeus planirostris } & 1.96 & 0.96 & 1.96 & 5.53 & \\
\hline & $1.81-2.08$ & $0.88-1.05$ & $1.69-2.26$ & $5.19-5.88$ & $32.6-39.0$ \\
\hline & 5 & 5 & 6 & 6 & \\
\hline
\end{tabular}

are postero-laterally oriented in all species except in $A$. caudifer, in which they are postero-ventrally oriented; these processes are strong and short in $D$. youngi, D. rotundus, $C$. auritus and $S$. erythromos, strong and long in A. planirostris, and slender and long in A. caudifer and M. microtis. In all species, the anterior articular foveae are antero-medially oriented, with the dorsal edge distinctly curved in $C$. auritus, and less curved in the remaining species. The posterior articular foveae are caudomedially oriented in all species, sub-squared in $D$. youngi and rounded in the other species, and is well separated in A. caudifer whereas they are close to each other in the other species.

Axis (Figs. 4, 5). In lateral view, the spinous process is high, short, sub-rectangular, and inclined anteriorly in $D$. youngi and $D$. rotundus (it can be also straight in $D$. rotundus). In $A$. caudifer, $C$. auritus, and A. planirostris, it is high, long, and ax-shaped, extending anteriorly and posteriorly beyond the neural arch, except in A. planirostris, where there is no posterior extension (see Table I). It is also important to mention that the anterior extension is well developed in C. auritus. In $M$. microtis the spinous process is low, short, subtriangular, and straight; and in S. erythromos is low, short, sub-rectangular, and inclined anteriorly (see Table I). The posterior edge of the neural arch is simple in all species (e.g. D. rotundus see Fig. 5a), except in $C$. auritus where a central tubercle and two deep concavities, at both sides of the spinous process and laterally delimited by a tubercle, can 


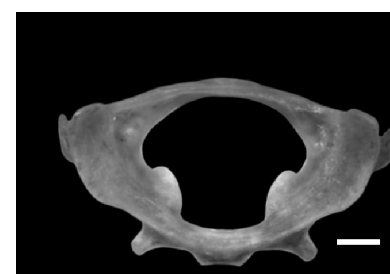

\section{dna}

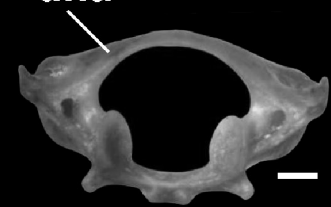

a

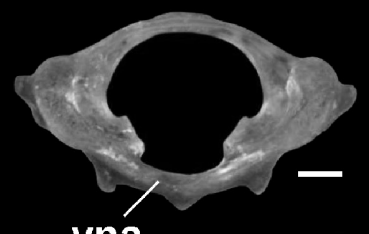

vna

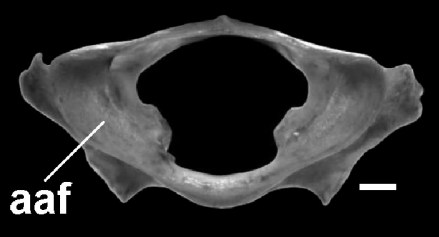

aaf

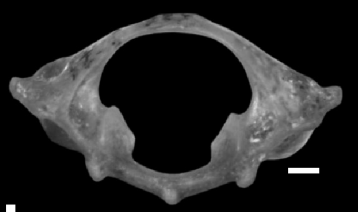

b

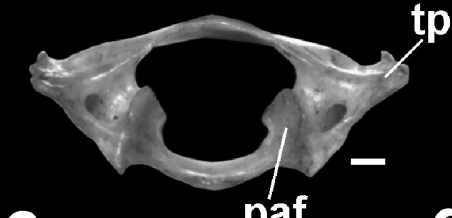

C d

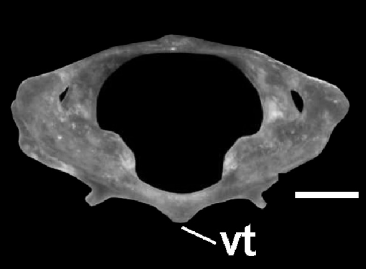

vt
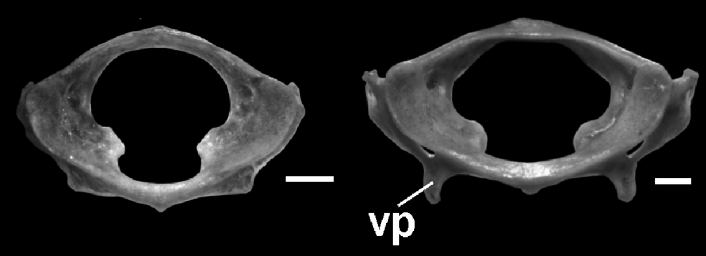

af

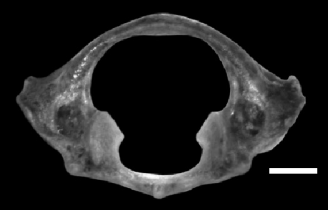

e

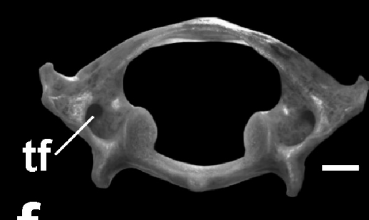

f
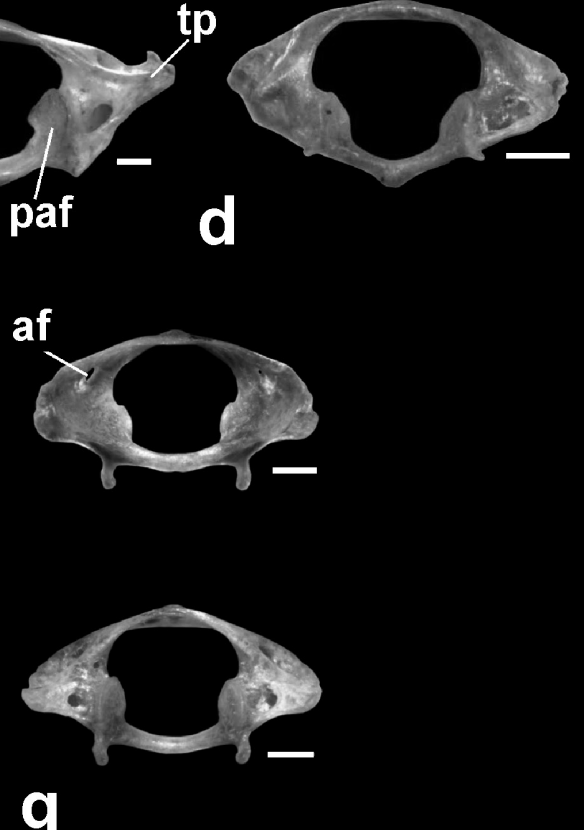

Figure 2 - Anterior (top) and posterior (bottom) views of atlas: a. Desmodus rotundus; b. Diaemus youngi; c. Chrotopterus auritus; d. Micronycteris microtis; e. Sturnira erythromos; f. Artibeus planirostris; g. Anoura caudifer. Acronyms: aaf: anterior articular fovea; af: atlantal foramen; dna: dorsal neural arch; paf: posterior articular fovea; tf: transverse foramen; tp: transverse process; vna: ventral neural arch; vp: ventral process; vt: ventral tubercle. Scale bar represents $1 \mathrm{~mm}$.

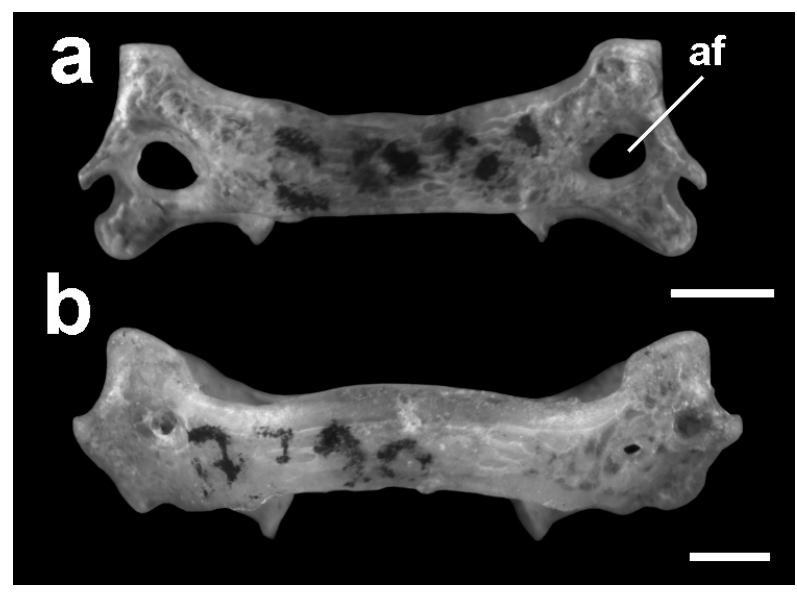

Figure 3 - Dorsal view of atlas: a) Anoura caudifer: very large atlantal foramen; b) Diaemus youngi: atlantal foramen with two openings. Acronyms: af: atlantal foramen. Scale bar represents $1 \mathrm{~mm}$. be observed (Fig. 5b). The transverse foramina are present and complete in all species, except in $M$. microtis and $S$. erythromos, where they are absent. The transverse processes are small in D. youngi and A. planirostris, well developed in D. rotundus and C. auritus (Fig. 5), and absent in M. microtis and $S$. erythromos; in A. caudifer they were not observed but probably because the material was broken.

In all species, the anterior articular foveae are proportionally similar in size, broad, dorsoventrally more developed, antero-laterally oriented, and posses a slightly convex surface; additionally, the foveae are sub-triangular in lateral view in most species but in some specimens they can be 


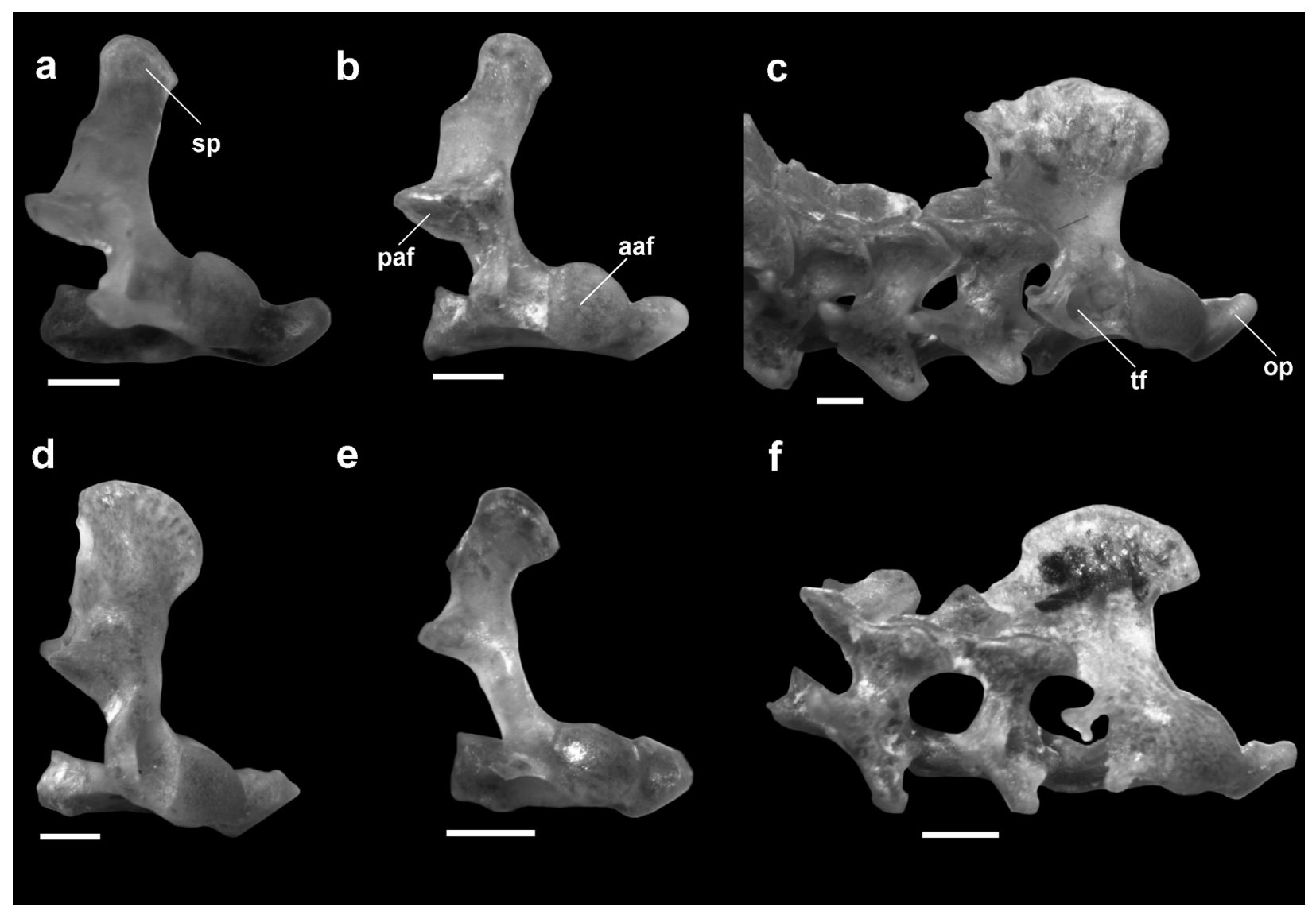

Figure 4 - Lateral view of axis: a. Desmodus rotundus; b. Diaemus youngi; c. Chrotopterus auritus; d. Artibeus planirostris; e. Sturnira erythromos; f. Anoura caudifer. Acronyms: aaf: anterior articular fovea; op: odontoid process; paf: posterior articular fovea; sp: spinous process; tf: transverse foramen. Scale bar represents $1 \mathrm{~mm}$.

rounded (D. rotundus) or oval (M. microtis). The posterior articular foveae are well-developed in $M$. microtis when compared with other species, ventrolaterally oriented, oval in D. youngi, M. microtis, $A$. planirostris and $S$. erythromos, and sub-triangular in $D$. rotundus, $A$. caudifer and C. auritus. The ventral tubercle is a ridge, posteriorly bifurcated into two smaller crests, present in D. youngi, D. rotundus, $A$. caudifer, and $S$. erythromos, but present or absent in C. auritus, M. microtis and A. planirostris. In lateral view, the odontoid process has an anterior orientation in S. erythromos and is antero-dorsally oriented in the other species (Fig. 4).

Posterior cervical vertebrae (C3-C7) (Fig. $6)$. Two equidistant processes on the middle of the posterior edge of the dorsal neural arches are present in D. youngi, D. rotundus, C. auritus, A. planirostris, and S. erythromos, and they can be present or absent in A. caudifer and M. microtis. The spinous process, when present, is tiny in $\mathrm{C} 5$ and $\mathrm{C} 6$ in D. rotundus (Fig. 6b), in $\mathrm{C} 3$ and $\mathrm{C} 7$ in C. auritus, and in C7 in S. erythromos. The preand post-zygapophysis articulation is oblique with regard to the sagittal plane. The location of the transverse processes varies in relation to the transverse foramina, and can be found at the same level (e.g. C3 in all species) or above (e.g. C5 and C6 in all species). In dorsal view, the transverse processes are posteriorly oriented in all except the following vertebrae and species: $\mathrm{C} 7$ slightly anterior in D. youngi and D. rotundus, C6 lateral and $\mathrm{C} 7$ anterior in $A$. caudifer, $\mathrm{C} 7$ anterior in M. microtis, and $\mathrm{C} 7$ lateral in C. auritus, A. planirostris, and S. erythromos (Figs. 6a, b). In 


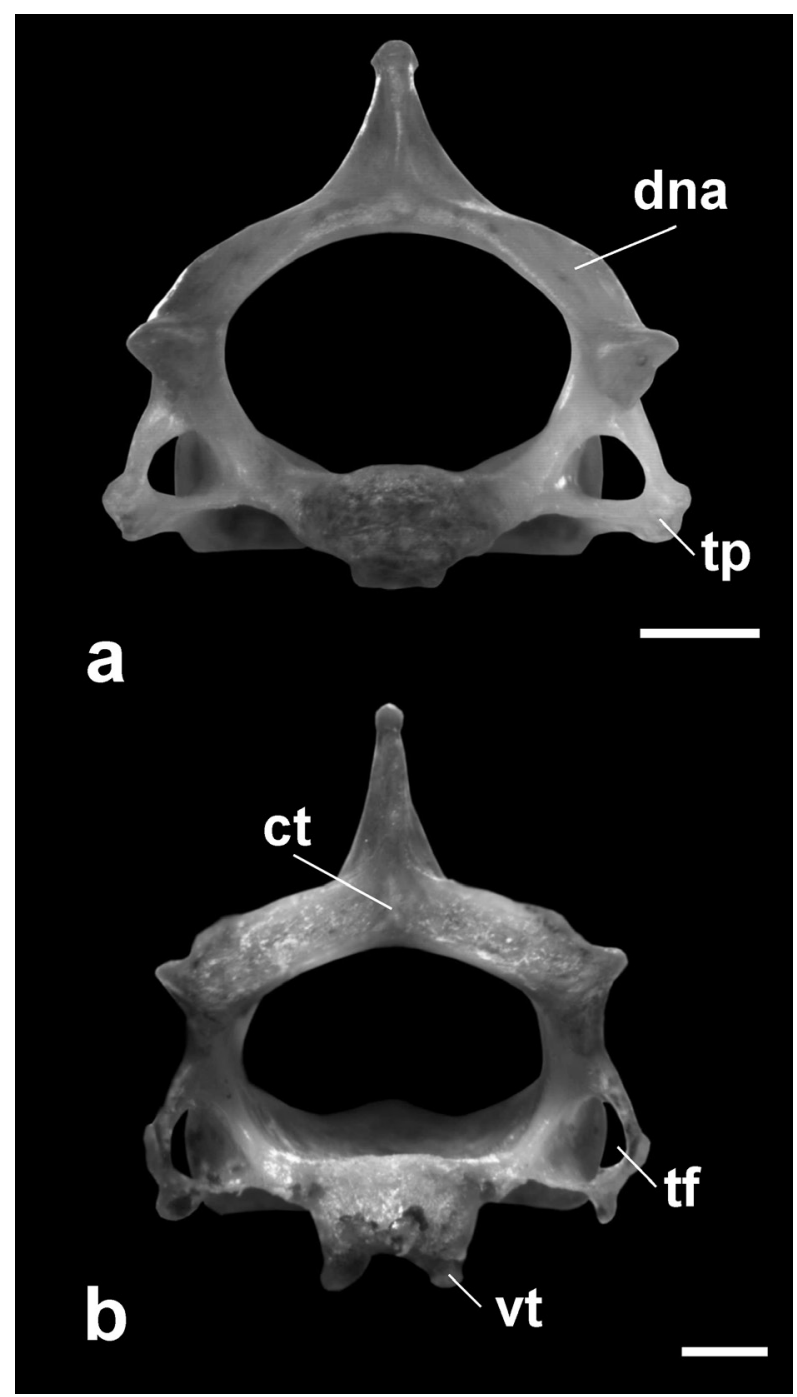

Figure 5 - Posterior view of axis: a. Desmodus rotundus: neural arch simple; b. Chrotopterus auritus: neural arch with a central tubercle and two concavities. Acronyms: ct: central tubercle; dna: dorsal neural arch; tf: transverse foramen; tp: transverse process; vt: ventral tubercle. Scale bar represents $1 \mathrm{~mm}$.

all species, the transverse foramina are absent in C7, except in one specimen of D. rotundus (CML 10124). The lamellae are antero-posteriorly developed and present in all vertebrae (Fig. 6c); an acute caudad projection can be observed on $\mathrm{C} 6$ in all species. The intervertebral spaces are broader in D. youngi, D. rotundus (Fig. 6b), M. microtis, and $S$. erythromos than in the rest of the species analyzed. In all species, the entire ventral surface (body and transverse process) of C3-5 is "V"-shaped. At C6 it is rectangular in D. youngi, D. rotundus, A. caudifer, and M. microtis and "V"-shaped in C. auritus, A. planirostris, and $S$. erythromos. At C7 it is square in D. youngi, D. rotundus, A. caudifer, M. microtis, and $S$. erythromos and rectangular in $C$. auritus and A. planirostris. In ventral view, the craniad region of the centrum is concave in all species, except in D. youngi, in which C7 is straight; and the caudad region is convex in $\mathrm{C} 3-6$ and straight in $\mathrm{C} 7$ in all species analyzed, except in D. youngi, in which C6 is straight.

Thoracic vertebrae (T1-11, 12 or 13) (Fig. 6). The number of thoracic vertebrae varies among species, being 11 in D. youngi, 12 in D. rotundus, 12 or 13 in A. planirostris, C. auritus, and $S$. erythromos, and 13 in A. caudifer and M. microtis. In all species, $\mathrm{T} 1$ is short and wide compared to the posterior cervical vertebrae, while the remaining thoracic vertebrae are longer and narrower, except some short vertebrae that are found in A. caudifer (T8-10) and in C. auritus (T9-11) (Fig. 6a). The general structure of the last two thoracic vertebrae of all species, and the last thoracic of $C$. auritus, are similar to the first lumbar vertebrae. Intervertebral spaces are present in A. caudifer, M. microtis, and $S$. erythromos. The development of the spinous processes is variable, being tiny or poorly developed in the first few vertebrae (e.g. T1-3 in $D$. youngi), absent in T4-6 (in all species), and well developed in the last few vertebrae (e.g. T9-12 in A. planirostris). Lateral ridges are present at both sides of the spinous processes in all vertebrae in D. youngi and D. rotundus (Fig. 6b), in T1-9 in A. caudifer, C. auritus, and S. erythromos, T2-5 in M. microtis, and T1-11 or 12 in A. planirostris. The transverse processes are present in all thoracic vertebrae of all species except $M$. microtis, where they are absent or small in T10-13. The transverse processes are separated from the mammillary processes in T9 in D. youngi and M. microtis, $\mathrm{T} 11$ in D. rotundus and A. planirostris, T10 in $A$. caudifer and $C$. auritus, and T13 in S. erythromos. The mammillary processes are present in the last 


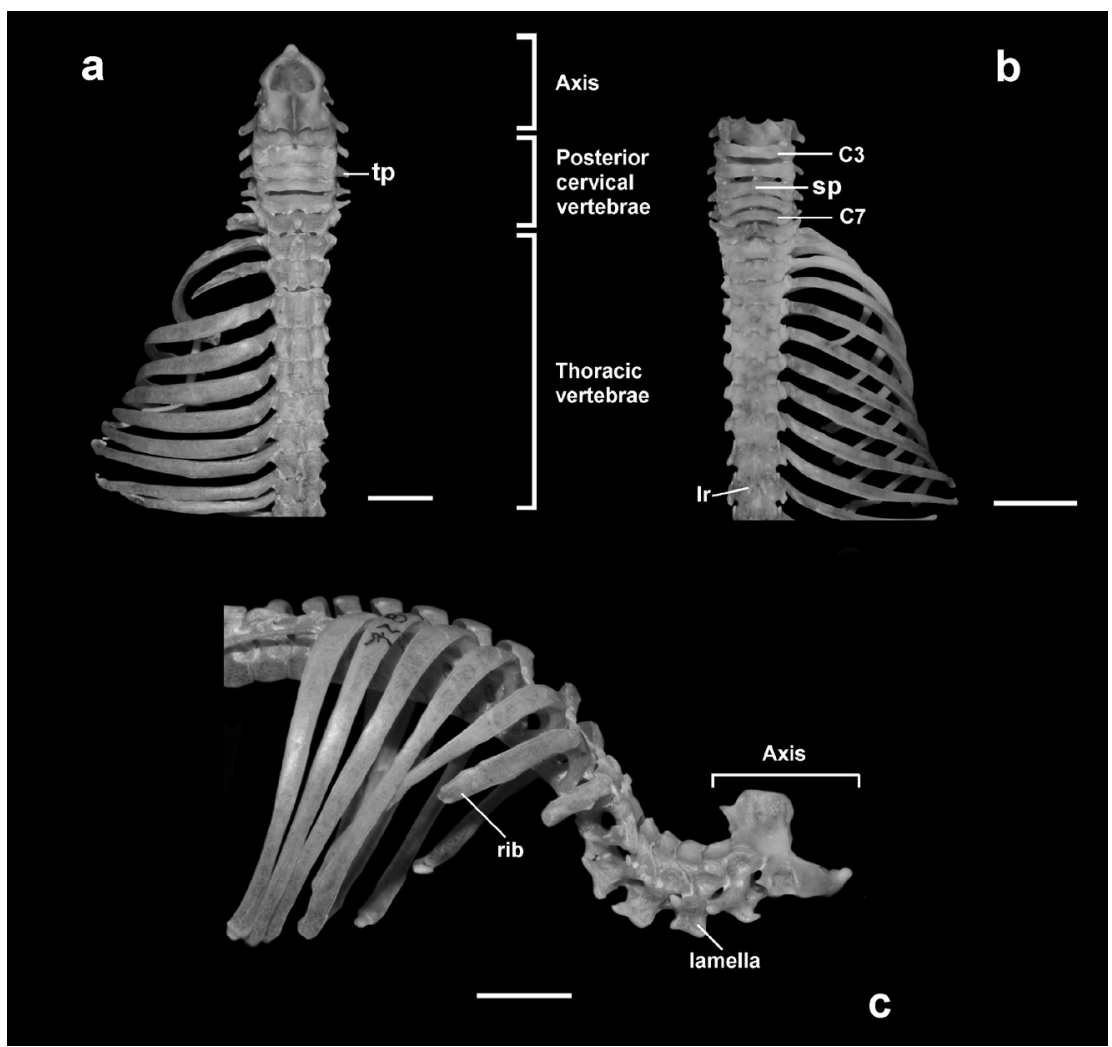

Figure 6 - Dorsal view of cervical and thoracic regions: a. Chrotopterus auritus; b. Desmodus rotundus. Lateral view of cervical and thoracic regions: c. Chrotopterus auritus. Acronyms: C3: third cervical vertebrae; C7: seventh cervical vertebrae; 1r: lateral ridge; sp: spinous process; tp: transverse process. Scale bar represents $5 \mathrm{~mm}$.

few vertebrae, on T9-11 in D. youngi, T10 and 12 in D. rotundus, $\mathrm{T} 7$ or T8-13 in A. caudifer, $\mathrm{T} 9$ or T1013 in C. auritus, T8-13 in M. microtis, T7 or T8-12 or T13 in A. planirostris, and in the last vertebra of $S$. erythromos. The accessory processes are absent in all species analyzed. The diaphragmatic vertebra (as defined by Argot 2003, Flores and Díaz 2009) was observed at T8 in D. youngi, T9 in $D$. rotundus, T12 in A. caudifer and C. auritus, T12 or 13 in M. microtis, and $\mathrm{T} 12$ in A. planirostris and $S$. erythromos.

Lumbar vertebrae (L1-4, 5 or 6) (Fig. 7). The number of lumbar vertebrae is different in the studied species, being four in A. caudifer, four or five in A. planirostris and S. erythromos, five in $M$. microtis, six in D. youngi and C. auritus, and five or six in D. rotundus.
In general, in all species, the first lumbar vertebrae are long and wide, becoming shorter and narrower towards the last vertebrae. In all species the spinous processes are low and long in relation with the vertebra, except in the last vertebra which reduces its length almost to one third (Fig. 7). The anticlinal vertebra, as defined by Flores and Díaz (2009), was observed only in L6 in D. youngi and $D$. rotundus. It is important to mention that in a specimen of D. rotundus (CML 7843) with only five lumbar vertebrae, the anticlinal vertebra was not observed. The transverse processes are present on L1-2 of D. youngi, on L1-3 of $D$. rotundus, L1-2 and 4 of $A$. caudifer, on all lumbar vertebrae of $C$. auritus (Fig. 7), on all vertebrae of M. microtis except in L1-3 where they can be present or absent, on L1-4/5 of A. planirostris, and all vertebrae except L2 of $S$. erythromos. The size 


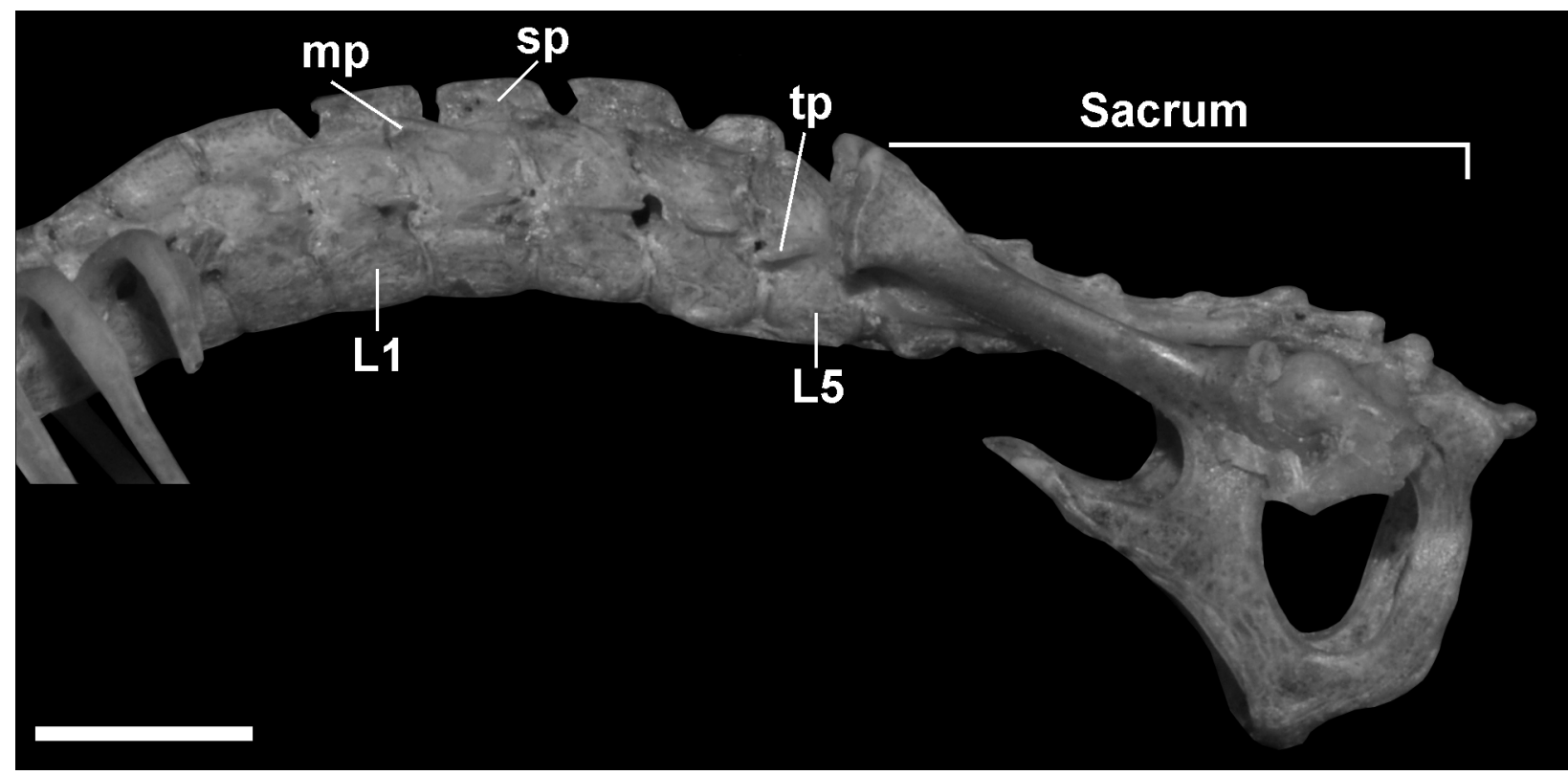

Figure 7 - Lateral view of lumbar vertebrae and sacrum of Chrotopterus auritus. Acronyms: L1: first lumbar vertebrae; L5: fifth lumbar vertebrae; mp: mammillary process; sp: spinous process; tp: transverse process. Scale bar represents $5 \mathrm{~mm}$.

and position of the processes are variable among species and vertebrae; for example they are well developed and posteriorly located in vampires and small and lateral in A. caudifer. The mammillary processes are antero-dorsally oriented in all species and can be well expanded in the first five lumbar vertebrae in $D$. youngi and D. rotundus, in the last lumbar of A. caudifer, C. auritus, and M. microtis, or all lumbar vertebrae in $A$. planirostris and $S$. erythromos (except L1 in the latter). Accessory processes are absent in all species.

Sacral vertebrae (Fig. 8). In order to determine the sacral vertebrae we have followed LópezGonzález and Polaco (2001) who define them as "those vertebrae fused with each other that may or not be articulated with the innominate and have spinous processes". All sacral vertebrae are fused together to form the sacrum (Flower 1885, Alférez 1990), which is wider in the anterior region and narrower in the middle and posterior regions. Some authors consider that the sacrum is formed by four or five completely fused vertebrae (Vaughan 1959, Altenbach 1979); in this study we could only distinguish the first three vertebrae, so it was not possible to determine the total number of elements.

Although $\mathrm{S} 1$ is fused, its boundaries are dorsally visible in all species except in vampires. The prezygapophyses are partially fused with the ilium in $A$. caudifer, A. planirostris, and $S$. erythromos, and completely fused in the other species. They are located surpassing the front edge of the ilium in A. planirostris, at the same level in A. caudifer, and behind in the other species (Figs. $8 \mathrm{c}-\mathrm{e})$. In all species, the $\mathrm{S} 1$ has the most robust vertebral body and, in lateral view, is oriented at an angle in relation to the antero-posterior axis of ilium, except in M. microtis in which it is parallel. The ventral tubercle is absent in D. youngi as well as in some specimens of $S$. erythromos. In lateral view, the sacrum is strongly convex and dorsally elevated with respect to the dorsal edge of the pelvis in vampires and in males of $C$. auritus (Figs. 8a, b). Dorsal and ventral intervertebral foramina can be observed, dorsals being smaller than ventrals (Fig. 8c). The spinous processes are fused, forming a crest, except in some specimens of 


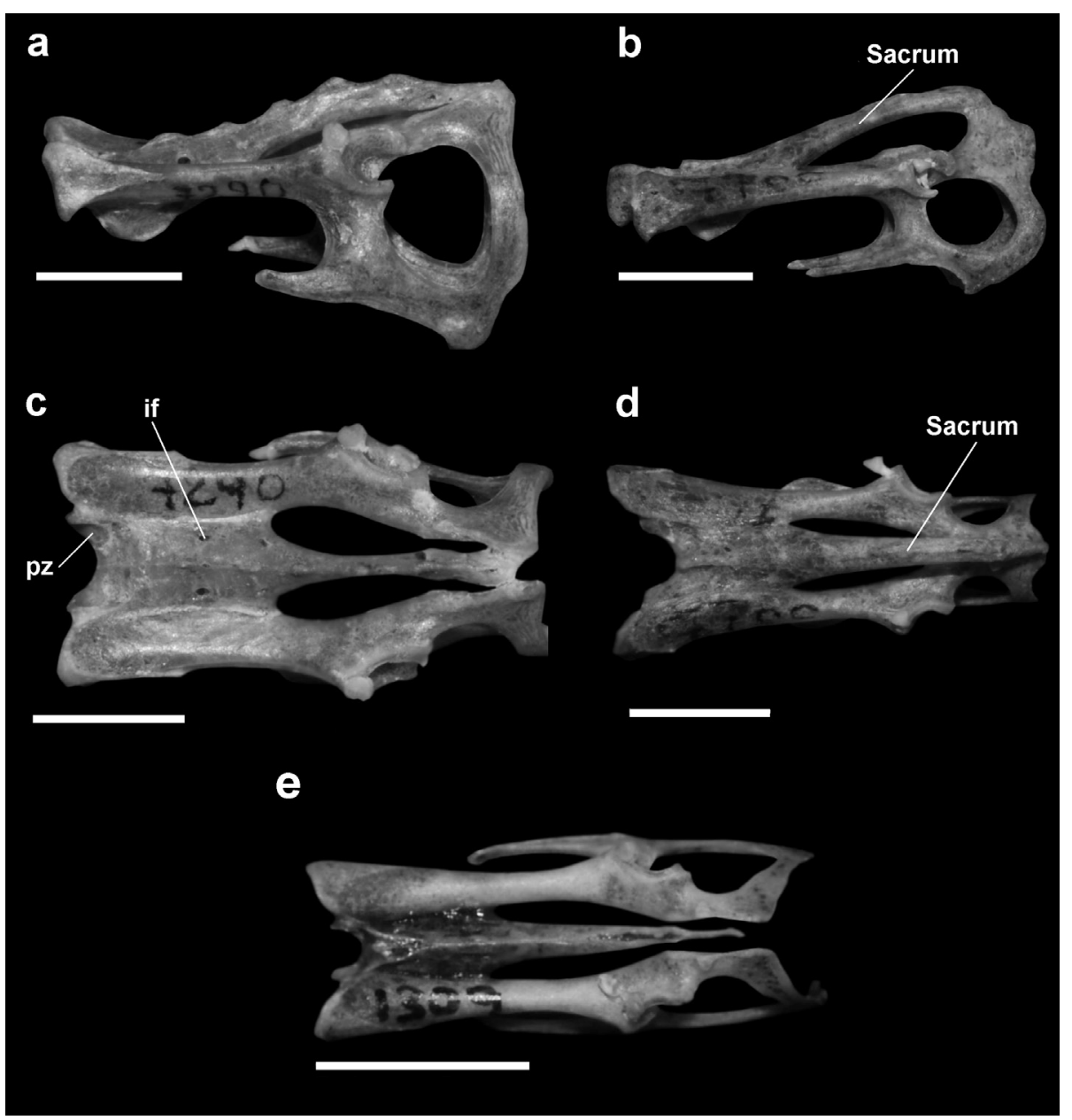

Figure 8 - Sacrum. Lateral view: a. Chrotopterus auritus; b. Desmodus rotundus. Dorsal view: c. Chrotopterus auritus; d. Desmodus rotundus; e. Sturnira erythromos. Acronyms: if: intervertebral foramina; pz: prezygapophysis. Scale bar represents $5 \mathrm{~mm}$.

C. auritus; the crest is, in general, more developed in the first sacral vertebrae, but is well developed throughout its length in $M$. microtis and $A$. caudifer. The transverse processes are completely fused so that the limits among them, or with the vertebrae, cannot be observed. In dorsal view, the mammillary processes in A. caudifer, C. auritus, M. microtis and A. planirostris are fused to form a crest, which can be barely visible in $C$. auritus, or very obvious in $A$. caudifer, $M$. microtis and $A$. planirostris.

Caudal vertebrae ( $\mathrm{Ca} 0,2,3$, or 6$)$. The caudal vertebrae are defined as "those placed after the sacrum and have no spinous processes" (López-
González and Polaco 2001). They were registered only in three of the studied species: A. caudifer, C. auritus, and M. microtis. Anoura caudifer has three small and simple caudals, with flat and wide vertebral bodies that decrease in size posteriorly. In C. auritus, two small and squared vertebrae can be observed. Micronycteris microtis has six vertebrae, the first two are short and wide, and the other are long and delicate, the Ca6 has a sharp tip and the articular fovea is absent.

Ribs. The number of pairs of ribs is variable among species, 11 in D. youngi, 12 in D. rotundus, 12 or 13 in A. planirostris, C. auritus and $S$. erythromos, 13 in A. caudifer and M. microtis. 


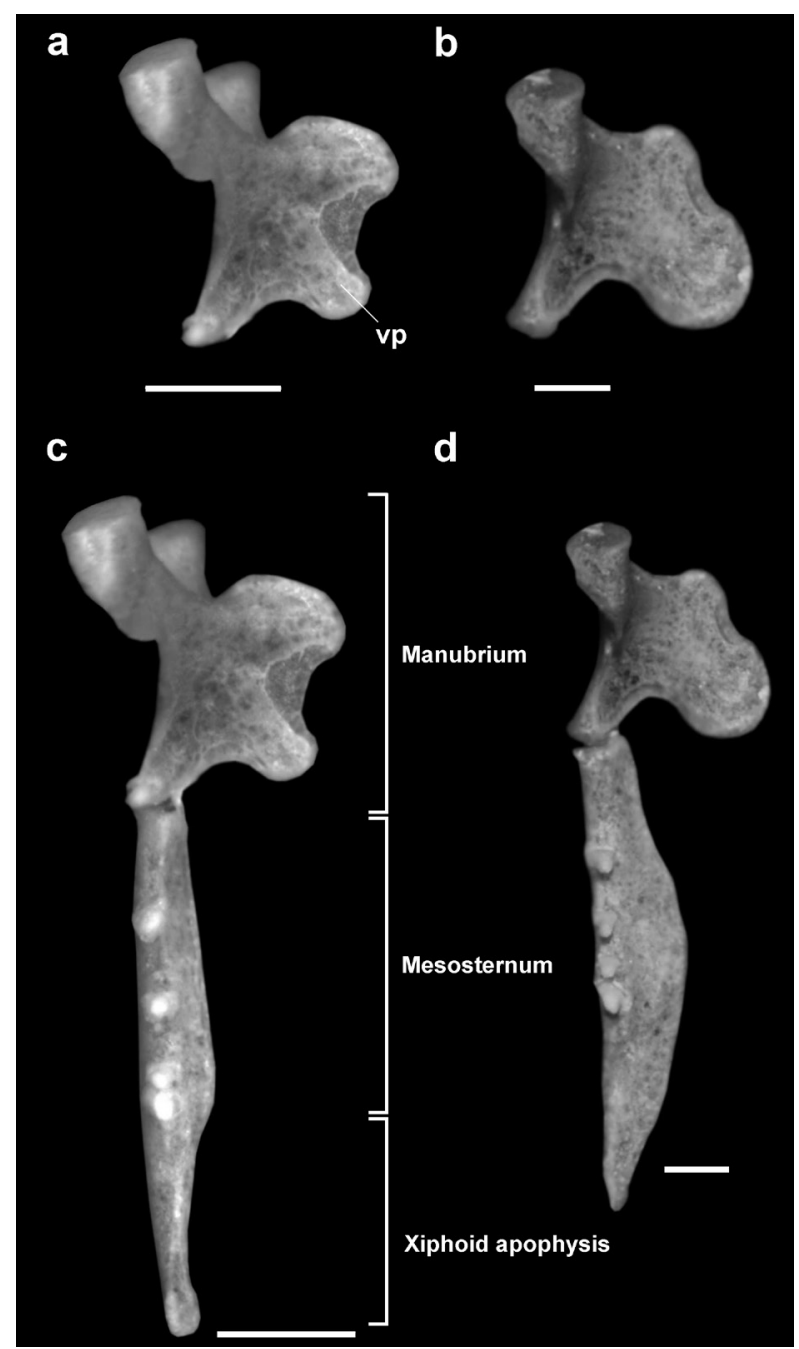

Figure 9 - Lateral view of sternum: a, c. Micronycteris microtis; b, d: Sturnira erythromos. Acronyms: vp: ventral process. Scale bar represents $1 \mathrm{~mm}$.

The number of true, false, and floating ribs is also variable, and all species analyzed have seven true pairs of ribs except $M$. microtis and $S$. erythromos which have six; three false pairs of ribs were recorded in D. youngi, D. rotundus, $C$. auritus, and A. planirostris, and four in A. caudifer, $M$. microtis, and S. erythromos; one floating pair of ribs was observed in D. youngi, two in D. rotundus, A. caudifer and $C$. auritus, and two or three in $M$. microtis, A. planirostris, and S. erythromos. The ribs can articulate with the vertebrae in two ways: a) at two points: the tubercle articulates with the

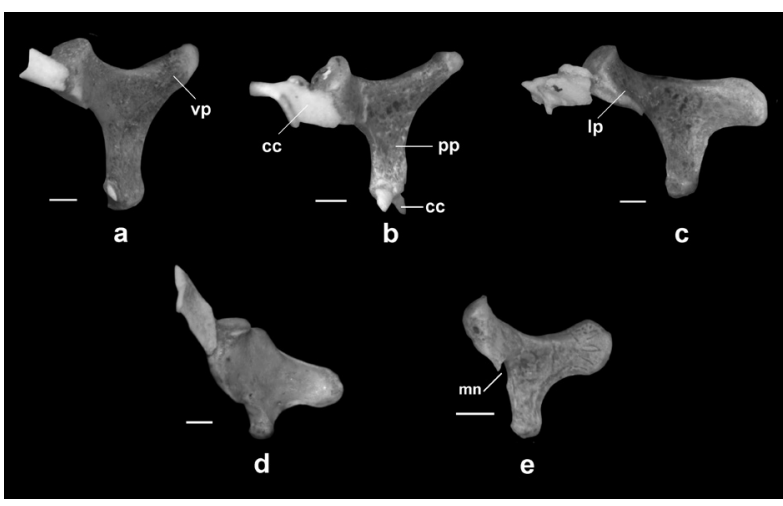

Figure 10 - Lateral view of manubrium of sternum: a. Desmodus rotundus; b. Diaemus youngi; c. Chrotopterus auritus; d. Artibeus planirostris; e. Anoura caudifer. Acronyms: cc: costal cartilage; lp: lateral process; mn: medial notch; pp: posterior process; vp: ventral process. Scale bar represents $1 \mathrm{~mm}$.

transverse process, and the capitulum articulates between the vertebral bodies of the vertebra that holds the rib and the preceding vertebra; or b) at one point: the capitulum articulates with the pedicle. In D. youngi and D. rotundus, all ribs articulate at two points, while in the other species the first 11 pairs of ribs articulate at two points and the last at only one point. The first pairs of ribs are small, robust, and transversally slender and tall, and the other ribs are transversally wide and flat in most species. However, in D. rotundus the second and third pairs are slender and tall, and in M. microtis and S. erythromos the ribs of the second pair are slender and tall. The articular foveae of the costal cartilages of the ribs are arranged in the lateral edges of the sternum in progressively shorter intervals.

Sternum (Figs. 9, 10). The sternum is subdivided into three regions: the manubrium, the body or mesosternum, and the xiphoid apophysis (Fig. 9). The manubrium is the most robust and complex element, the body is the longest, and the xiphoid apophysis is the simplest and least developed. The number of sternebrae or sternal pieces (including the manubrium and xiphoid apophysis) is variable: five or six in $S$. erythromos, six in M. microtis, seven in D. youngi, D. rotundus, A. caudifer and $A$. 
planirostris, and seven in males $(\mathrm{n}=8)$ and eight in females $(\mathrm{n}=1)$ of $C$. auritus. In all species, the manubrium is T-shaped and has a prominent keel or ventral process and well expanded lateral processes (Figs. 9, 10). The posterior edge of the lateral processes can have a medial notch which is variable, and can be hardly visible in D. youngi, $D$. rotundus, and $C$. auritus, slightly evident to well-marked in A. caudifer (Fig. 10e), slightly evident to absent in $M$. microtis, and well-marked or closed and forming a foramen in A. planirostris and $S$. erythromos. The ventral process, or keel, is simple in all species but bilobed with an anterior and a posterior expansion in $M$. microtis and $S$. erythromos (the bilobed shape is less marked in some specimens of S. erythromos, Figs. 9a, b). The angle between the body of the manubrium and the keel is $90^{\circ}$ in $A$. caudifer (Fig. 10e), greater than $90^{\circ}$ (angling craniad) in D. youngi and D. rotundus (Figs. 10a, b), and less than $90^{\circ}$ (angling caudad) in C. auritus and A. planirostris (Figs. 10c, d). In $M$. microtis and $S$. erythromos, the anterior expansion of the keel is more than $90^{\circ}$ and the posterior is less than $90^{\circ}$ (Figs. 9a, b). The posterior portion is barely expanded posteriorly in M. microtis, A. planirostris, and S. erythromos, expanded in $D$. youngi, A. caudifer, and C. auritus, and well expanded in $D$. rotundus. In all species, the body of the sternum is elongated and in each stenebra a central constriction is observed, but less marked in M. microtis, A. planirostris and S. erythromos. In all species, the sternebrae are fused; the ventral crest is well developed in A. caudifer, A. planirostris and $S$. erythromos, moderately developed in $M$. microtis, and slightly developed in D. youngi, D. rotundus and $C$. auritus. The costal cartilages articulate in the mesosternum with different sternebrae, with third to sixth in M. microtis and S. erythromos, third to sixth or seventh in D. rotundus, third to seventh in D. youngi, A. caudifer and A. planirostris, and third to seventh or eighth in $C$. auritus. The last costal cartilage always articulates with the union of the mesosternum with the xiphoid apophysis. In all species, the second costal cartilages articulate in the latero-posterior edge of the posterior process. In ventral view, the xiphoid apophysis is subtriangular in all species except in S. erythromos, where is sub-cylindrical; a crest entering from the mesosternum can be observed in some species $(A$. caudifer, $C$. auritus, and S. erythromos) and in some specimens of $A$. planirostris. The anterior border of the xiphoid apophysis and the last sternebra of the mesosternum are fused only in $C$. auritus, $M$. microtis, A. planirostris, and S. erythromos.

\section{DISCUSSION}

The axial skeleton of five of the species analyzed (A. caudifer, M. microtis, C. auritus, S. erythromos, and $A$. planirostris) has not been previously described, and for the vampire bats (D. rotundus and $D$. youngi) we are adding new observations for some elements of the axial skeleton.

Based on this study and information obtained from the literature (Vaughan 1959, Walton and Walton 1970a, Altenbach 1979, López-González and Polaco 2001), we propose a range in the number of vertebrae for the family Phyllostomidae as follows: 11-13 thoracic, 4-6 lumbar, 1 sacrum, and 0-12 caudals. The cervical region and the sternum show evident morphological patterns, while in the rest of the regions few remarkable characteristics were observed.

In the cervical region the first two vertebrae are the most developed, with the atlas being the largest, and its general structure matches with descriptions given by other authors (Walton and Walton 1970a, b, 1973, Fenton and Crerar 1984, López-González and Polaco 2001). It is important to mention that although Fenton and Crerar (1984) indicated little variability in the axis in Yangochiroptera and Yinpterochiroptera, we observed remarkable differences in this bone among the species analyzed. The axis is the only 
cervical vertebra with a spinous process developed and well defined; the transverse processes and foramina can be present or absent, but the apparent absence in specimens of $M$. microtis may be the result of an error in preparing the skeletons. In one specimen of $S$. erythromos (CML 7708), we observed a broken foramen and the absence of the transverse processes, but in the other specimens of this species, as well as in S. oporaphilum, traces of the arch of the transverse foramen can be present or absent. It is noteworthy that in the most complete descriptions of skeletons of bats, such as Vaughan $(1959,1970 b)$ and Altenbach (1979), the atlas and axis were not included, but in Fenton and Crerar (1984) the two bones were described, and in Walton and Walton (1973) only the atlas was described. These two vertebrae are very important when morpho-functional interpretations are made, related to different movements of the head (Argot 2003), and become more important in phyllostomids because they have broad movements of the head during flight and feeding activities (Walton and Walton 1973).

Additionally, our observations of the spinous and transverse processes of the posterior cervical vertebrae are coincident with what was already observed by other authors (Flower 1885, Walton and Walton 1970a, b, Altenbach 1979, López-González and Polaco 2001), except for the transverse processes in D. youngi and D. rotundus, here described as weakly developed, while Altenbach (1979) considered them as well developed.

Two different patterns were observed in the cervical region:

a) The spinous process of the axis with anterior extensions, the atlas and C3 with long dorsal neural arches (see Table I), the close articulation between axis and $\mathrm{C} 3$, and the narrow intervertebral spaces, which would imply less sagittal movements of the head and neck. This pattern was observed in $A$. caudifer, C. auritus, and A. planirostris; but it is important to clarify that $A$. caudifer and $C$. auritus have a caudad extension in the spinous process of the axis, which implies a greater lateral movement. In C. auritus, this extension and the development of the occipital crest in the skull indicates strong neck musculature, which could be related with the predaceous habits (see Flores and Díaz 2009);

b) The spinous process of the axis without anterior extensions, the atlas and C3 with short dorsal neural arches (see Table I), the articulation between axis and C3 well apart or separated, and the broader intervertebral spaces, which would imply most movements of head and neck. This was recorded in the remaining species, being more evident in $M$. microtis and S. erythromos (see Fenton and Crerar 1984, Sargis 2001, Argot 2003, Flores and Díaz 2009, Carrizo and Díaz 2013). The morphology of these vertebrae could be related with the development of the muscles and with the type of diet and the way food is obtained by each species.

However, other patterns were observed in the studied species, such as:

a) Anterior articular foveae of the axis broader and better developed dorso-ventrally, which would imply a greater rotational movement of the head around the longitudinal axis;

b) Pre- and post-zygapophyses of the posterior cervical vertebrae (including postzygapophysis of the axis) oblique, suggesting a greater resistance to lateral and rotational movements, which would give greater rigidity to the spine, but at the same time the oblique position would indicate the flexion of the neck in a sagittal plane;

c) Transverse processes of the axis and the most posterior cervical vertebrae oriented posteriorly which would imply a greater mobility of the neck in a sagittal plane; 
d) Remarkable development of the lamellae, especially in C6, which would indicate a great development of the flexor muscles of the head (see Argot 2003).

The general anatomy of the atlas, added to the presence of the ventral processes in phyllostomids, could increase attachment surface of the muscles to support the head during flight, feeding, and resting activities (Walton and Walton 1973), although until now we have not found a clear pattern in the ventral processes that is related with the feeding habit. On the other hand, the orientation of the transverse processes of the atlas could change the position of the head (Walton and Walton 1973), although we have not found differences in the orientation of these processes in the analyzed species.

It is important to mention that while Wille (1954) observed modifications of muscles of the throat (tongue and floor of the mouth), typical of nectarivorous species, in this study we have found similarities in the region of the neck between $A$. caudifer and some species belonging to other trophic guilds.

Finally, according the results obtained in this study the vertebral anatomy of the cervical region not only reflects the relationship with the roosting position, looking up and scanning the surroundings (Fenton and Crerar 1984), but also it is related with the way of getting food as well as with the type of food (e.g. the carnivorous bats capture struggling large prey while for bats of non-carnivorous guilds the food is motionless).

Walton and Walton (1970a) indicated that in most bats the thoracic vertebrae lack spinous processes, but in some species analyzed in this study, different degrees of development were observed in these processes; Simmons and Conway (2001) mentioned these processes in the family Mormoopidae. In some thoracic vertebrae, lateral crests, tiny or more developed were observed, which are something that were not recorded in other mammals (Flower 1885, Argot 2003, Flores and
Díaz 2009, Carrizo and Díaz 2013). These crests are the point of origin for a portion of the trapezius muscle, whose insertion can be found in different regions of the clavicle and scapula (Vaughan 1959, Altenbach 1979). The vampires are the only group that has these well-developed crests in all vertebrae, and they could be related with the capability for terrestrial locomotion and initial flight, because these muscles are related to jumping (Altenbach 1979). The number of thoracic vertebrae varies (Dobson 1878, Walton and Walton 1970a) and in this study, for example, the lowest number was recorded in vampires, while the highest was observed in nectarivorous and insectivorous bats.

According to Bell (1836), the lumbar vertebrae are similar to the thoracic vertebrae in their general shape and the small spinous processes. Small spinous processes were not observed in phyllostomid thoracic vertebrae in our study, although the thoraco-lumbar area has similarities among the vertebral elements as in the cervicothoracic area. On the other hand, the variability in the development of the transverse processes of the seven species of phyllostomid bats, matches with the observations of Vaughan (1959), Altenbach (1979), and López-González and Polaco (2001).

In the sacral region, the vertebrae are fused forming the sacrum. In the studied species, we could only distinguish the first three vertebrae, which differ from the observations of other authors (Vaughan 1959, Walton and Walton 1970a, b, Altenbach 1979, Simmons 1994) who mention more than three vertebrae. It is important, however, to note that Walton and Walton (1970a) mentioned their difficulties in establishing the boundaries between the sacral vertebrae.

Among the analyzed species, the ischiatic tuberosity is fused to the posterior portion of the sacrum only in vampire bats, a characteristic that was also observed in species of the families Pteropodidae, Vespertilionidae, Mormoopidae, and Noctilionidae(Walton and Walton 1970a, Altenbach 
1979, Simmons and Conway 2001). Another exclusive character observed in desmodontines was the remarkable curvature of the sacrum in relation with the pelvis.

The caudal vertebrae are simple and the vertebral body is the only visible structure, which has been noted by other authors (Walton and Walton 1970a, b, Altenbach 1979, López-González and Polaco 2001); this region presents an important variation in the number of vertebrae. Micronycteris microtis, with a tail completely included in the uropatagium (Díaz et al. 2011), has the greatest number of caudal vertebrae compared with the other species analyzed, and is the only insectivore species studied. The high number of caudal vertebrae could be related with its feeding habits, that is, the capture of insects perched on leaves. The use of the uropatagium for capturing their prey has been well documented in vespertilionid bats (Webster and Griffin 1962).

We observed few differences in the ribs; in the two species of vampire bats, all ribs are articulated in two points, while in the other species the first 11 pairs of ribs articulate at two points and the last at only one point. In $D$. rotundus the first three pairs of ribs are slender and tall, a difference from all other species analyzed.

Large variations were observed in the sternum. In the majority of families of bats (Vaughan 1959, Walton and Walton 1970a, Simmons and Conway 2001, DesRoche et al. 2007), the manubrium has a simple ventral process, a character that was also observed throughout the sample analyzed in this study with the exception of two species. In $M$. microtis and $S$. erythromos a bilobed process was recorded; this was also observed in Vampyressa pusilla (P.J. Gaudioso et al., unpublished data) and in species of the families Pteropodidae, Furipteridae, and Nycteridae (Walton and Walton 1970a, Norberg 1972, DesRoche et al. 2007 figs. 2b, e). This differs from the observations by Simmons (1994, p. 3) who indicated that a bilobed keel on the manubrium is an unusual character, according to what she found in Pteropodidae. The variation of the angle of the ventral process (see Results for details) was also observed by other authors (Vaughan 1959, Walton and Walton 1970a, b, Simmons and Conway 2001) in members of the families Vespertilionidae, Molossidae, and Mormoopidae. In this process, tendons and muscles, as M. pectoralis, originate and provide the major force to the downstroke of the wing in flight (Dobson 1878, Vaughan 1959, 1970b, Altenbach 1979). The variation of the angle seems not to be related to diet or way of obtaining food, because species with different diets and feeding behaviors have identical angles. For example, some insectivorous species such as Dasypterus ega (see Baird et al. 2015 for the use of Dasypterus), Lasiurus cinereus (Vespertilionidae), Molossus molossus, and Tadarida brasiliensis (Molossidae), and the sanguivorus D. youngi and $D$. rotundus have an angle greater than $90^{\circ}$; in the piscivorous Noctilio leporinus (Noctilionidae) and the nectarivorous A. caudifer, Glossophaga morenoi, and Glossophaga soricina, the angle is $90^{\circ}$, and in the frugivorous A. planirostris, Uroderma magnirostrum, and Pygoderma bilabiatum, and the carnivorous $C$. auritus, the angles are less than $90^{\circ}$.

It is important to mention that, in a recent revision of the morphological diagnoses of phyllostomid bats, Cirranello et al. (2016) considered the unique position of the ventral process of the manubrium at a 90 degree angle as an 'unambiguously derived synapomorphy' of the family Phyllostomidae. We found other variations in some characters that were considered by Cirranello et al. (2016) also as unambiguously derived synapomorphies (P.J. Gaudioso et al., unpublished data). For this reason, it is fundamental to make detailed description of the mammalian postcranium including a broad spectrum of species in order to establish reliable morphological patterns and not make generalizations based on observations of few taxa and/or specimens. These considerations are 
important, especially for researchers who intend to use large databases that have not been carefully examined to verify their accuracy in small details that could affect their findings and conclusions.

Based on the observed characters in the sternum the species were grouped as follow: a) sanguivorous: angle between the body of the manubrium and the keel greater than $90^{\circ}$ (D. rotundus - D. youngi), b) insectivorous frugivorous: the anterior expansion of the keel is more than $90^{\circ}$ and the posterior is less than $90^{\circ}(\mathrm{M}$. microtis - S. erythromos), c) nectarivorous: angle between the body of the manubrium and the keel is $90^{\circ}$ (A. caudifer), and d) carnivorous - frugivorous: angle between the body of the manubrium and the keel less than $90^{\circ}$ (C. auritus - A. planirostris).

It should be mentioned that no sexual dimorphism was found in any structure of the axial skeleton in any of the species analyzed.

Although the food type consumed by some bats can be explained by anatomical studies of skulls, teeth, and mandibles (Freeman 1981, 1984, 1988, 1995, 1998), the differences and similarities we observed in the axial skeleton allow us to infer that some skeletal elements have been modified as a result of anatomical requirements involved in the mode of obtaining food rather than with the type of food. In the same way as DesRoche et al. (2007) suggested that some modifications of the thoracic skeletal morphology is associated with laryngeal echolocation beyond those related to flight. We believe these analyzed patterns cannot be explained solely on the bases of the anatomical structure. Instead, the patterns represent important bases that can be refined as more data and information on the natural history, habitat preferences, shelters, food habits, locomotion, behavior, and evolutionary history of the group, are obtained. Such basic data are clearly interrelated in complex ways, and are still lacking for the majority of the studied species.

In the future, in order to complete and improve the description of the axial skeleton, it will be important to include morphometric and morphogeometric analyses of different skeletal elements (e.g. atlas, axis) as well as to study the postnatal development in diaphanized specimens of different species and families of bats.

\section{ACKNOWLEDGMENTS}

We thank all the members of the Programa de Investigaciones de Biodiversidad Argentina (PIDBA) and Programa de Conservación de los Murciélagos de Argentina (PCMA) for their help and support in the fieldwork. The study was funded by Consejo de Investigaciones de la Universidad Nacional de Tucumán (CIUNT) and Consejo Nacional de Investigaciones Científicas y Técnicas (CONICET).

\section{REFERENCES}

ALFÉREZ F. 1990. Mamíferos. In: Meléndez B (Ed), Paleontología. Editorial Paraninfo. Madrid, p. 1-24.

ALTENBACH JS. 1979. Locomotor morphology of the Vampire Bat, Desmodus rotundus. Am Soc Mamm, Sp Pub 6: 1-137.

ARGOT C. 2003. Functional-adaptative anatomy of the axial skeleton of some extant marsupials and the paleobiology of the Paleocene marsupials Mayulestes ferox and Pucadelphys andinus. J Morphol 255: 279-300.

BAIRD AB, BRAUN J, MARES MA, MORALES JC, PATTON JC, TRAN CQ AND BICKHAM JW. 2015. Molecular systematic revision of tree bats (Lasiurini): doubling the native mammals of the Hawaiian Islands. J Mammal 96(6): 1255-1274.

BAKER RJ, SOLARI S, CIRRANELLO A AND SIMMONS NB. 2016. Higher level classification of phyllostomid bats with a summary of DNA synapomorphies. Acta Chiropt 18: $1-38$.

BELL T. 1836. Cheiroptera. In: Todd BR (Ed), The cyclopaedia of anatomy and physiology. Sherwood, Gilbert and Piper, London, UK, p. 594-600.

CARRIZOLVANDDÍAZMM. 2013. Descripción morfológica del esqueleto axial de filotinos (Rodentia: Sigmodontinae): aspectos morfofuncionales y filogenéticos. Mastozool Neotrop 20: 7-29.

CIRRANELLO A, SIMMONS NB, SOLARI S AND BAKER RJ. 2016. Morphological diagnoses of higher-level phyllostomid taxa (Chiroptera: Phyllostomidae). Acta Chiropt 18: 39-71. 
DESROCHE K, FENTON MB AND LANCASTER WC. 2007. Echolocation and the thoracic skeletons of bats: a comparative morphological study. Acta Chiropt 9:483494.

DÍAZ MM, AGUIRRE LF AND BARQUEZ RM. 2011. Clave de identificación de los murciélagos del cono sur de Sudamérica. Centro de Estudios en Biología Teórica y Aplicada. Cochabamba, Bolivia, $94 \mathrm{p}$.

DOBSON GE. 1878. Catalogue of the chiroptera in the collection of the British Museum. Taylor and Francis Limited. London, $567 \mathrm{p}$.

FENTON MB AND LM CRERAR. 1984. Cervical vertebrae in relation to roosting posture in bats. J Mammal 65: 395403.

FLORES DA AND DÍAZ MM. 2009. Postcranial skeleton of Glironia venusta (Didelphimorpha, Didelphidae, Caluromyinae): Description and functional morphology. Zoosyst Evol 5: 311-339.

FLOWER WH. 1885. An introduction to the osteology of the mammalia. MacMillian \& Co. London, UK, 412 p.

FREEMAN PW. 1981. Correspondence of food habits and morphology in insectivorous bats. J Mammal 62: 166-173.

FREEMAN PW. 1984. Functional cranial analysis of large animalivorous bats (Microchiroptera). J Linn Soc 2: 387408.

FREEMAN PW. 1988. Frugivorous and animalivorous bats: Dental and cranial adaptations. J Linn Soc 33: 249-272.

FREEMAN PW. 1995. Nectarivorous feeding mechanisms in bats. J Linn Soc 56: 439-463.

FREEMAN PW. 1998. Form, function, and evolution in skulls and teeth of bats. In: Kunz TH and Racey PA (Eds), Bat biology and conservation Smithsonian Institution Press. Washington and London, p 140-156.

GUNNELL GF AND SIMMONS NB. 2005. Fossil evidence and the origin of bats. J Mamm Evol 12: 209-246.

HAUTIER L, WEISBECKER V, SÁNCHEZ-VILLAGRA MR, GOSWAMI A AND ASHER RJ. 2010. Skeletal development in sloths and the evolution of mammalian vertebral patterning. Proc Natl Acad Sci USA 107: 1890318908.

LARKEY D, DATWYLER SL AND LANCASTER WC. 2012. Vertebral fusion in bats: phylogenetic patterns and functional relationships. In: Gunnell GF and Simmons NB (Eds), Evolutionary history of bats: fossil, molecules and morphology, New York, Cambridge University Presss, p. 500-529.

LÓPEZ-GONZÁLEZ C AND POLACO OJ. 2001. Descripción y variación del esqueleto postcraneal de Glossophaga morenoi Martínez y Villa-R 1938 (Chiroptera: Phyllostomidae). Acta Zool Mex 83: 1-28.

MARTINEZ S. 2010. Paleontology of the Mount Etna bat fauna, coastal eastern Queensland. Unpublished $\mathrm{Ph}$.
D. thesis, Biogeosciences Queensland University of Techonology. Queensland.

MORGAN CC. 2009. Geometric morphometrics of the scapula of South American caviomorph rodents (Rodentia: Hystricognathi): form, function and phylogeny. Mamm Biol 74: 497-506.

NORBERG UM. 1972. Functional osteology and myology of the wing of the dog-faced bat Rousettus aegyptiacus (E. Geoffroy) (Mammalia, Chiroptera). Z Morphol Tiere 73: $1-44$.

NORBERG UM AND RAYNER JMV. 1987. Ecological morphology and flight in bats (Mammalia: Chiroptera): wing adaptations, flight performance, foraging strategy and echolocation. Phil Trans Roy Soc B 316: 335-427.

NOVACEK MJ. 1987. Auditory Features and Affinities of the Eocene Bats Icaronycteris and Palaeochiropteryx (Microchiroptera, incertae sedis). Am Mus Novit 2877: 1-18.

O'LEARY MA ET AL. 2013. Response to comment on 'The placental mammal ancestor and the post-K-Pg radiation of placentals'. Science 339: 662-667.

PANYUTINA AA, KORZUN LP AND KUZNETSOV AN. 2015. Forelimb morphology of bats. In: Panyutina A, Korzun LP and Kuznetsov AN (Eds), Flight of Mammals: From terrestrial limbs to wings. Springer International Publishing Switzerland, p. 115-203.

PROCHEL J AND SÁNCHEZ-VILLAGRA MR. 2003. Carpal ontogeny in Monodelphis domestica and Caluromys philander (Marsupialia). Zool 106: 73-84.

ROJAS D, WARSI OM AND DÁVALOS LM. 2016. Bats (Chiroptera: Noctilionoidea) challenge a recent origin of extant Neotropical diversity. Syst Biol 65(3): 432-448.

SALTON JA AND SARGIS EJ. 2008. Evolutionary Morphology of the Tenrecoidea (Mammalia) Forelimb Skeleton. In: Sargis EJ and Dagosto M (Eds), Mammalian Evolutionary Morphology: A Tribute to Frederick S. Szalay. Dordrecht: Springer Science+Business Media B.V., p. 51-71.

SARGIS EJ. 2001. A preliminary qualitative analysis of the axial skeleton of tupaiids (Mammalia, Scadentia): functional morphology and phylogenetic implications. J Zool 253: 473-483.

SARGIS EJ. 2007. The postcranial morphology of Ptilocercus lowii (Scandentia, Tupaiidae) and its implications for primate supraordinal relationships. In: Ravosa MJ and Dagosto M (Eds), Primate Origins: Adaptations and Evolution. New York: Springer Science+Business Media, LLC, p. 51-82.

SARGIS EJ AND DAGOSTO M (Eds). 2008. Mammalian Evolutionary Morphology: A Tribute to Frederick S. Szalay. Springer. Dordrecht, The Netherlands, 439 p.

SHAPIRO L. 1995. Functional Morphology of lndrid Lumbar Vertebrae. Am J Phys Anthrop 98: 323-342. 
SIMMONS NB. 1994. The case for chiropteran monophyly. Am Mus Novit 3103: 1-54.

SIMMONS NB AND CONWAY TM. 2001. Phylogenetic relationships of mormoopid bats (Chiroptera: Mormoopidae) based on morphological data. Bull Am Mus Nat Hist 258: 1-97.

TAVARES VC. 2008. Revisionary systematics and phylogeny of Vampyressa and Stenodermatinae (Chiroptera: Phyllostomidae). Unpublished Ph. D. thesis, University of New York. New York, The City, USA.

TAYLOR WR AND VAN DYKE GC. 1985. Revised procedures for staining and clearing small fishes and other vertebrates for bone and cartilage study. Cybium 9: 107119.

TEJEDOR A. 2011. Systematics of funnel-eared bats (Chiroptera: Natalidae). Bull Am Mus Nat Hist 353: 1-140.

VAUGHAN TA. 1959. Functional Morphology of Three Bats: Eumops, Myotis, Macrotus. Mus Nat Hist, University of Kansas, USA 12: 1-153.

VAUGHAN TA. 1966. Morphology and flight characteristic of molossid bats. J Mammal 47: 249-260.

VAUGHAN TA. 1970a. The transparent dactylopatagium minus in phyllostomatid bats. J Mammal 51: 142-145.

VAUGHAN TA. 1970b. The skeletal system. In: Wimsatt WA (Ed), Biology of bats Academic Press. New York, USA, p. $98-139$.

VAUGHAN TA AND BATEMAN GC. 1970. Functional morphology of the forelimb of mormoopid bats. J Mammal 51: 217-235.

VELAZCO PM. 2005. Morphological Phylogeny of the Bat Genus Platyrrhinus Saussure, 1860 (Chiroptera:
Phyllostomidae) with the Description of Four New Species. Fieldiana Zool NS 105: 1-53.

WALTON DW AND WALTON GM. 1970a. Post-cranial osteology of bats. In: Slaughter BH AND Walton DW (Eds), About bats Southern Methodist University Press. Dallas, USA, p 93-126.

WALTON DW AND WALTON GM. 1970b. The post-craneal osteology of Chilonycteris psilotis. Rev Biol Trop 17: 147163.

WALTON DW AND WALTON GM. 1973. Considerations on the osteology and myology of the upper cervical region in Phyllostomatidae. Korean J Zool 16: 149-160.

WEBSTER FA AND GRIFFIN DR. 1962. The role of the flight membranes in insect captures by bats. Anim Behav 10: 332-340.

WETTERER AL, ROCKMAN MV AND SIMMONS NB. 2000. Phylogeny of Phyllostomid bats (Mammalia: Chiroptera): data from diverse morphological systems, sex chromosomes, and restriction sites. Am Mus Novit 248: $1-200$.

WILLE A. 1954. Muscular adaptation of the nectar eating bats (subfamily Glossophaginae). Trans Kansas Acad Sci 57: 315-325.

\section{SUPPLEMENTARY MATERIAL}

Appendix S1 - Analyzed specimens by families. For each specimen, the localities are listed by country, alphabetically by province and then by specific site, department and coordinates between parentheses, numbers of specimens, collection acronym and number, and sex. The acronym used in the text is CML (Colección Mamíferos Lillo). 